\title{
Peningkatan Profesionalitas Guru SD/MI, SMP/MTS, dan SMA/SMK/MA Kota Surakarta Melalui Penelitian Tindakan Kelas Pada Masa Pandemi Covid-19
}

\author{
Sugiaryo, Sutoyo, Toha Syahbani \\ Universitas Slamet Rlyadi \\ sugiaryo@unisri.ac.id
}

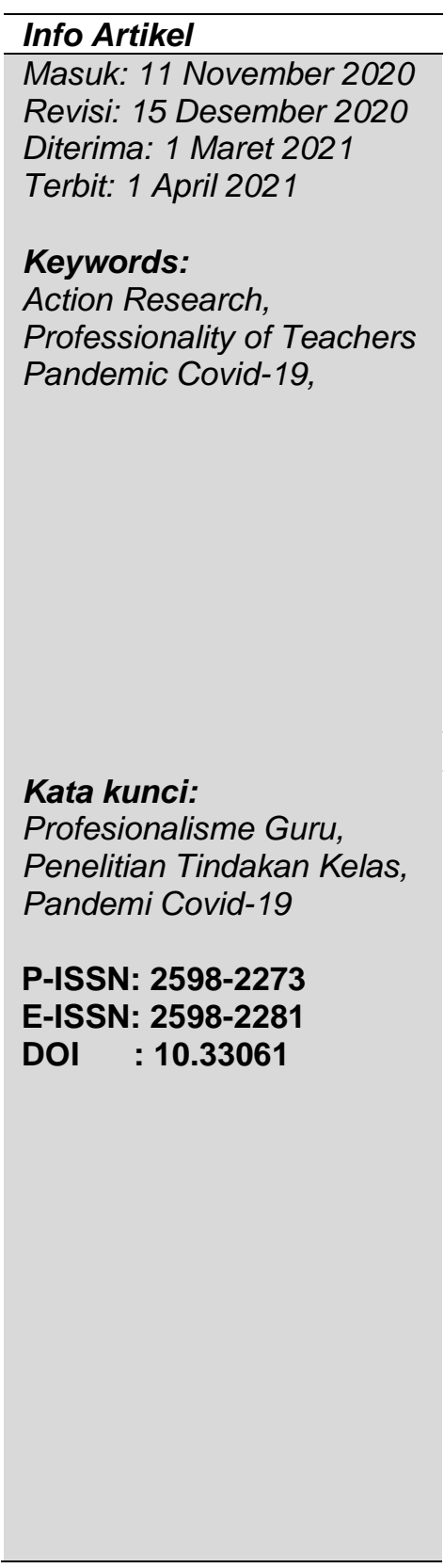

\begin{abstract}
This community service program is carried out for teachers of SD / MI, SMP / MTS, and SMA / SMK / MA Surakarta City. The purpose of this service is to provide understanding and improve the professionalism of SD / MI, SMP / MTS, and SMA / SMK / MA teachers in Surakarta City through Classroom Action Research during the Covid-19 pandemic. From the results of the discussion, most of the teachers of SD / MI, SMP / MTS, and SMA / SMK / MA do not understand and are not used to doing Classroom Action Research properly. Given that scientific work in the form of Classroom Action Research is one of the requirements in proposing promotion. Due to the lack of interest in making scientific papers, as a result they are hampered in proposing promotions. The method of implementing community service used is webinars (lectures and discussions) and mentoring through WhatsApp (WA) social media. This community service program has the following outcomes, namely: (1) Increased understanding of SD / MI, SMP / MTS, and SMA / SMK / MA teachers about classroom action research; (2) The realization of class action research proposals; and (3) Publications in scientific journals.
\end{abstract}

\begin{abstract}
Abstrak
Program pengabdian masyarakat ini dilakukan pada guru-guru SD/MI, SMP/MTS, dan SMA/SMK/MA Kota Surakarta. Tujuan dari pengabdian ini adalah memberikan pemahaman dan meningkatkan profesionalitas guru-guru SD/MI, SMP/MTS, dan SMA/SMK/MA Kota Surakarta melalui Penelitian Tindakan Kelas pada masa pandemi Covid-19. Dari hasil diskusi, sebagian besar guru-guru SD/MI, SMP/MTS, dan SMA/SMK/MA kurang memahami dan belum terbiasa melakukan Penelitian Tindakan Kelas secara baik. Mengingat karya ilmiah berupa Penelitian Tindakan Kelas adalah merupakan salah satu salah satu syarat dalam mengajukan kenaikan pangkat. Dikarenakan minimnya minat membuat karya tulis ilmiah itulah, akibatnya mereka terhambat dalam usulan kenaikan pangkatnya. Metode pelaksanaan pengabdian masyarakat yang digunakan adalah webinar (ceramah dan diskusi) dan pendampingan melalui media sosial WhatsApp (WA). Program pengabdian masyarakat ini memiliki luaran yaitu: (1) Meningkatnya pemahaman guru-guru SD/MI, SMP/MTS, dan SMA/SMK/MA tentang penelitian tindakan kelas; (2) Terwujudnya proposal penelitian tindakan kelas; dan (3) Publikasi di jurnal ilmiah.
\end{abstract}

\section{PENDAHULUAN}

Guru adalah pemegang jabatan dan pekerja profesional. Banyak yang menganggap seperti itu, namun pada kenyataannya implementasi di lapangan masih jauh dari itu. Ukuran professional seorang guru salah satunya dari sisi siswa adalah 
jika kelas yang mereka ikuti menjadi surga dalam kegiatan belajar, sehingga mereka menanti kehadiran guru di kelas ( Sugiyanto, 2009)

Ekawarna (2010), menegaskan bahwa dalam pembelajaran, berkembangnya profesionalitas guru dapat dicermati sewaktu mengajar di kelas, membimbing peserta didik, mendampingi peserta didik dalam penelitian, terutama penelitian tindakan kelas, serta berbagai aktivitas pendidik yang berhubungan dengan proses pembelajaran, baik di ruang kelas maupun di luar ruangan kelas, seperti peningkatan perencanaan, pengorganisasian, pelaksanaan dan evaluasi program pembelajaran.

Upaya guru dalam meningkatkan kualitas kelas berupa mutu isi, kemudian mutu masukan, mutu proses dan mutu hasil kegiatan pembelajaran di dalam kelas adalah tahap-tahap pelaksanaan penelitian tindakan kelas. Pada akhirnya peningkatan tersebut bisa digunakan dalam meningkatkan sikap professional seorang guru serta meningkatkan budaya akademik di lingkungan sekolah hingga tercipta sikap proaktif dalam mingkatkan mutu pembelajaran secara kontinyu .

Penelitian Tindakan Kelas adalah penelitian tindakan (action research) yang dilaksanakan oleh guru di dalam kelas. John Eliot, menjelaskan bahwa penelitian tindakan adalah sebuah kajian dari situasi sosial dengan tujuan memperbaiki mutu tindakan dalam situasi sosial tersebut (Hopkins, 1993). Sedangkan Mc Taggart, menyebutkan bahwa pengertian penelitian tindakan dijelaskan sebagai sebuah kegiatan yang dilakukan dalam rangkaperbaikan diri sendiri, menambah pengalaman kerja diri sendiri serta dilaksanakan secara sistematis, terstruktur, terencana, dan dengan sikap mawas diri (Kemmis S. \& Mc Taggart, 1988). Suharsini Arikunto (2006), menjelaskan bahwa penelitian tindakan kelas merupakan kegiatan pengamatan pada kegiatan belajar siswa dalam bentuk perbuatan yang sengaja dibuat serta diwujudkan di dalam situasi sebuah kelas secara bersamaan. Tindakan ini biasanya dilakukan oleh seorang guru atau oleh seorang siswa dengan arahan dari guru.

Penelitian Tindakan Kelas memiliki karakteristik tertentu yang berbeda dengan penelitian formal. karakteristik tersebut antara lain : (1). Perbaikan proses pembelajaran dari dalam; (2). Usaha kolaboratif antara guru dan dosen; dan (3). Bersifat fleksibel (Hopkins, 1993). Sedangkan Rachman Natawidjaya (2009), mengemukakan bahwa penelitian tindakan kelas, memiliki ciri-ciri sebagai berikut : (1). Dirancang untuk menanggulangi masalah nyata di tempat (kelas) yang bersangkutan; 
(2). Diterapkan secara kontektual sesuai dengan keadaan dan sasaran yang ada; (3). Fokus pada peningkatan kinerja guru di kelas; (4). Bersifat fleksibel; (5). Data berdasarkan pengamatan atau perilaku serta refleksi peneliti; (6). Menyerupai penelitian eksperimental, namun tidak ketat memperdulikan pengendalian variabel; (7). Umumnya dilakukan dalam bentuk studi kasus.

Perbaikan atau peningkatan mutu atau kualitas praktek pembelajaran di dalam kelas adalah tujuan dari sebuah kegiatan penelitian tindakan kelas. Melalui PTK ini guru senantiasa dituntut untuk memperbaiki praktek kegiatan pembelajaran di dalam kelas sesuai dengan kondisi langsung di lapangan yang nyata berdasarkan wawasan keilmuan dan penguasaan teori praktis pembelajaran. Ekawarna (2010), menjelaskan bahwa tujuan PTK adalah : (1). Memperbaiki mutu praktek pembelajaran di kelas; (2). Meningkatkan kinerja pembelajaran yang dilaksanakan guru; (3). Menemukan dan mengatasi masalah pembelajaran di kelas; (4). Menemukan dan mengeksplorasi model-model pembelajaran yang inovatif untuk dapat diterapkan di kelas; (5). Mencobakan gagasan, pikiran, kiat, cara, dan solusi baru pembelajaran untuk meningkatan mutu pembelajaran

Obyek Penelitian Tindakan Kelas pada hakekatnya dalam rangka meningkatkan mutu dan hasil pembelajaran di kelas. Sarwiji (2009), menyebutkan bahwa komponen-komponen yang mempengaruhi proses dan hasil pembelajaran di kelas, meliputi : (1). Siswa; (2) Guru; (3). Materi pelajaran; (4). Media pembelajaran; (5) Lingkungan pembelajaran; dan (6). Menejemen sekolah. Sedangkan Suharsimi Arikunto (2006), mengemukakan bahwa obyek penelitian tindakan kelas meliputi : (1). Unsur siswa; (2). Unsur guru; (3). Unsur materi pembelajaran; (4). Unsur peralatan atau sarana pembelajaran; (5). Unsur hasil pembelajaran; (6). Unsur lingkungan; dan (7). Unsur pengelolaan.

Kenyataan di lapangan menunjukkan bahwa dari kurang lebih 6000 guru yang berstatus PNS di kota Surakarta yang memiliki pangkat/jabatan Pembina Tk. I/IV-B sejumlah 58 orang dan yang berpangkat Pembina / IV-A sejumlah 3084 orang guru (data dari Dikpora, Pebruari 2019). Hal ini menunjukkan bahwa guru yang berpangkat/jabatan IV-A enggan mengusulkan kenaikan pangkat/jabatan. Keengganan ini disebabkan karena adanya beberapa kendala antara lain; (1). Lemahnya pemahaman terhadap konsep dan prinsip penelitian tindakan kelas, (2). 
Tidak tersedianya anggaran untuk melakukan penelitian tindakan kelas, (3). Tidak tersosialisasinya budaya berupa reflecting thinking berupa portofolio (berupa catatan kinerja berkelanjutan) yang dibuat sendiri sesuai keadaan yang sebenarnya, dan (4). Kurangnya jumlah pembimbing dalam melakukan penelitian di sekolah.

Berdasarkan pemikiran tersebut, maka melalui dana Universitas Slamet Riyadi Surakarta, diajukan usul pengabdian dengan judul "Peningkatan Profesionalitas Guru SD/MI, SMP/MTS, dan SMA/SMK/MA Kota Surakarta Melalui Penelitian Tindakan Kelas Pada Masa Pandemi Covid-19"

\section{METODE PELAKSANAAN}

Pihak-pihak yang terlibat dalam pengabdian kepada masyarakat ini adalah: (1) Pengurus PGRI tingkat kota, tingkat cabang, dan tingkat ranting; (2) Dinas Pendidikan Kota Surakarta dalam hal ini bidang pendidikan dasar; (3) Tim Pengabdian Kepada Masyarakat dari Progdi PPKN FKIP UNISRI.

Metode dan tahapan dalam pelaksanaan pengabdian ini dapat dideskripsikan sebagai berikut:

1. Tahap Sosialisasi

Pada tahap ini dilakukan rapat koordinasi antara tim pengabdian kepada masyarakat Progdi PPKN FKIP UNISRI dengan Pengurus PGRI Kota, Pengurus Cabang, dan Pengurus Ranting secara daring.

2. Tahap Pelaksanaan

Pada tahap ini diselenggarakan:

a. Webinar tentang "Peningkatan Profesionalisme Guru di Masa Pandemi Covid-19.

b. Pendampingan membuat proposal PTK melalui media sosial WhatsApp.

3. Tahap Pendampingan

Pada tahap ini dilaksanakan setelah tahap pelaksanaan. Pendampingan ini dilakukan untuk mendampingi guru-guru yang melaksanakan penelitian tindakan kelas. Karena masih dalam masa pandemi Covid-19, maka pendampingan PTK dilakukan setelah masa pandemi Covid-19.

Untuk lebih jelasnya tahapan dan pelaksanaan pengabdian ini digambarkan sebagai berikut: 


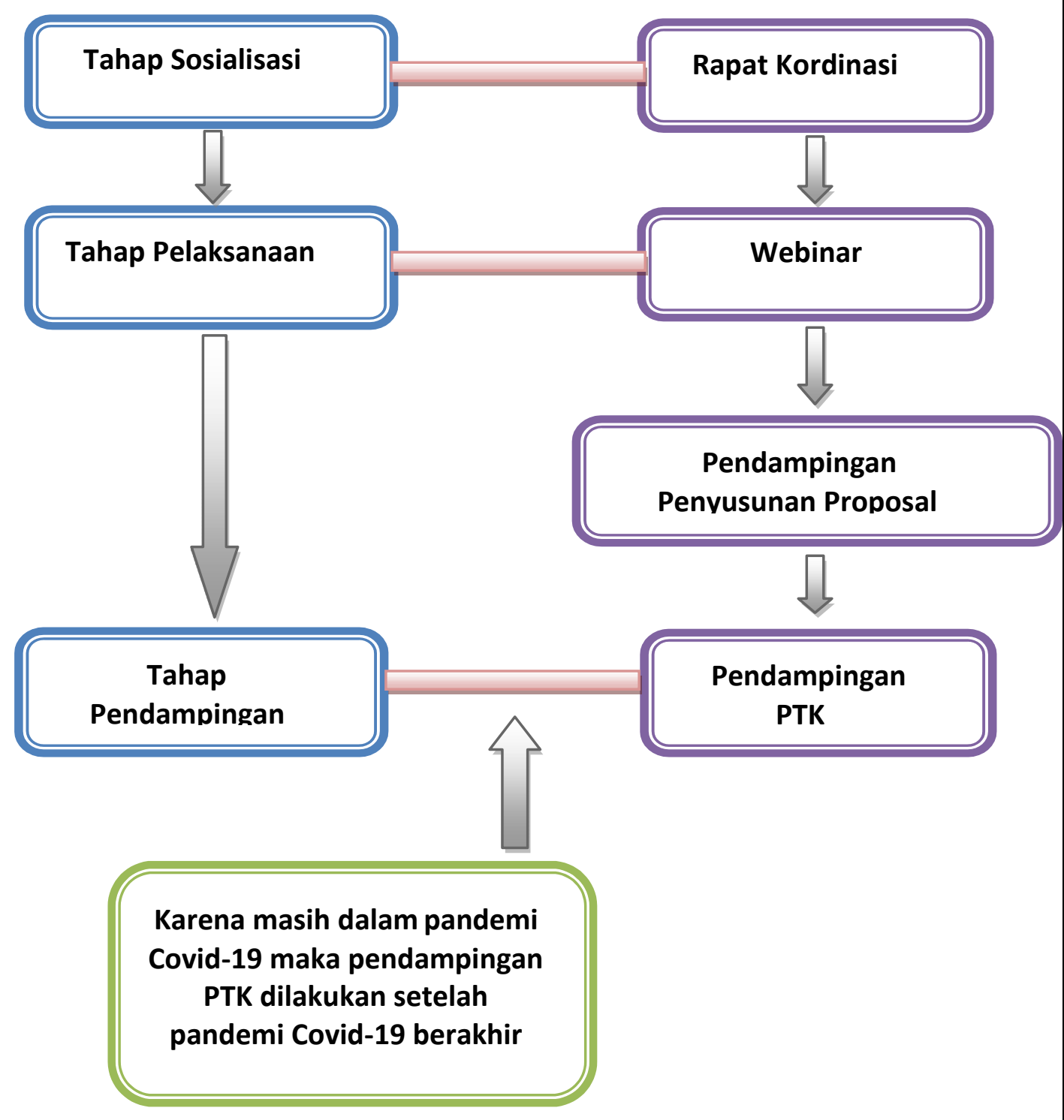

\section{PEMBAHASAN}

1. Webinar

Peningkatan profesionalisme guru SD/MI, SMP/MTS, dan SMA/SMK/MA pada masa pandemi Covid-19 dimulai dengan kegiatan wabinar. Webinar peningkatan profesionalisme guru ini lebih dititikberatkan pada penulisan karya tulis ilmiah berupa penelitian tindakan kelas. Metode webinar ini digunakan karena pemahaman dan kebiasaan guru SD/MI, SMP/MTS, dan SMA/SMK/MA tentang penelitian tindakan kelas belum cukup memadai. Webinar ini diikuti oleh 220 peserta yang berasal dari guru-guru SD/MI, SMP/MTS, dan SMA/SMK/MA se-Kota Surakarta. Webinar ini yang semula akan diselenggarakan di kantor PGRI Kota Surakarta. Karena sesuatu hal, kegiatan ini dilaksanakan di SMK Negeri 4 Surakarta, pada tanggal 25 Juli 2020. Pada 
webinar ini menggunakan aplikasi Zoom dan YouTube melalui link https://www.youtube.com/watch?v=iq-DSqL8HzA\&t=3429s

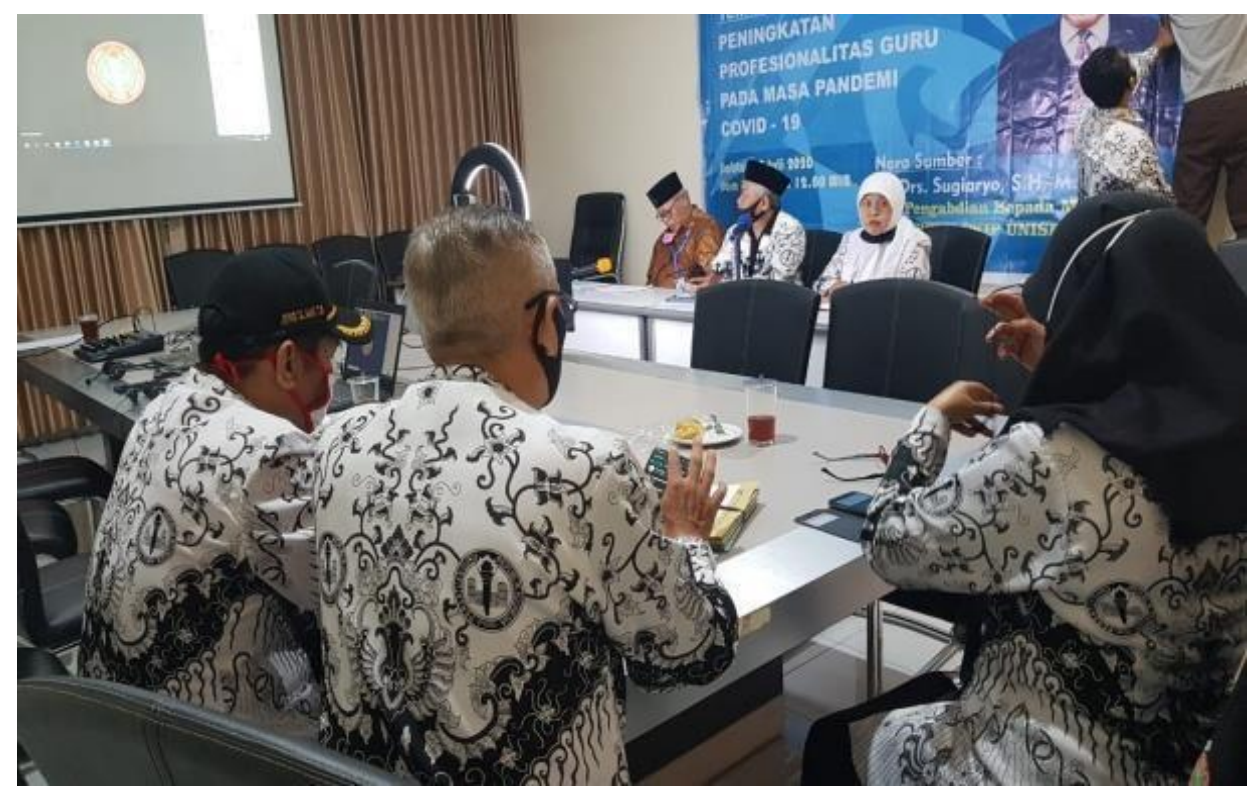

Gambar 1. kegiatan webinar dan diskusi

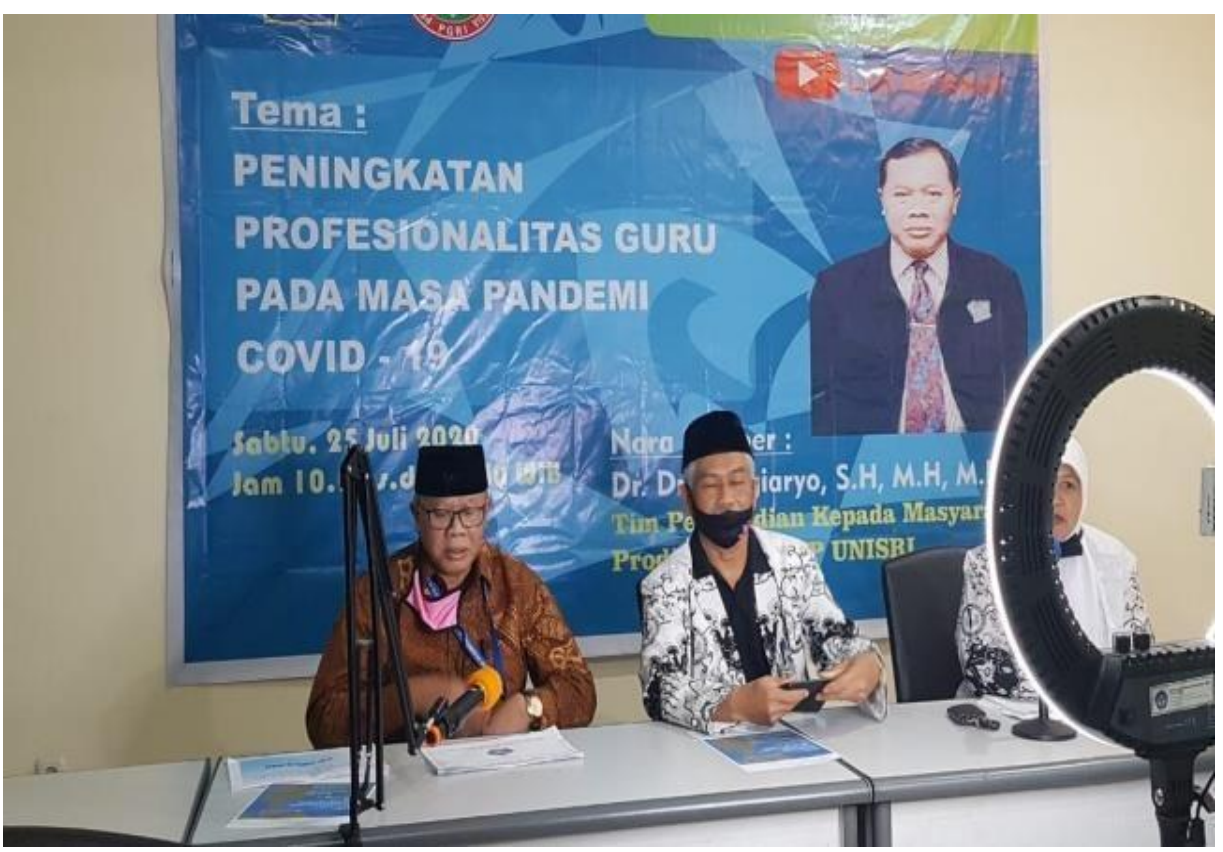

Gambar 2. kegiatan webinar dan diskusi (2) 


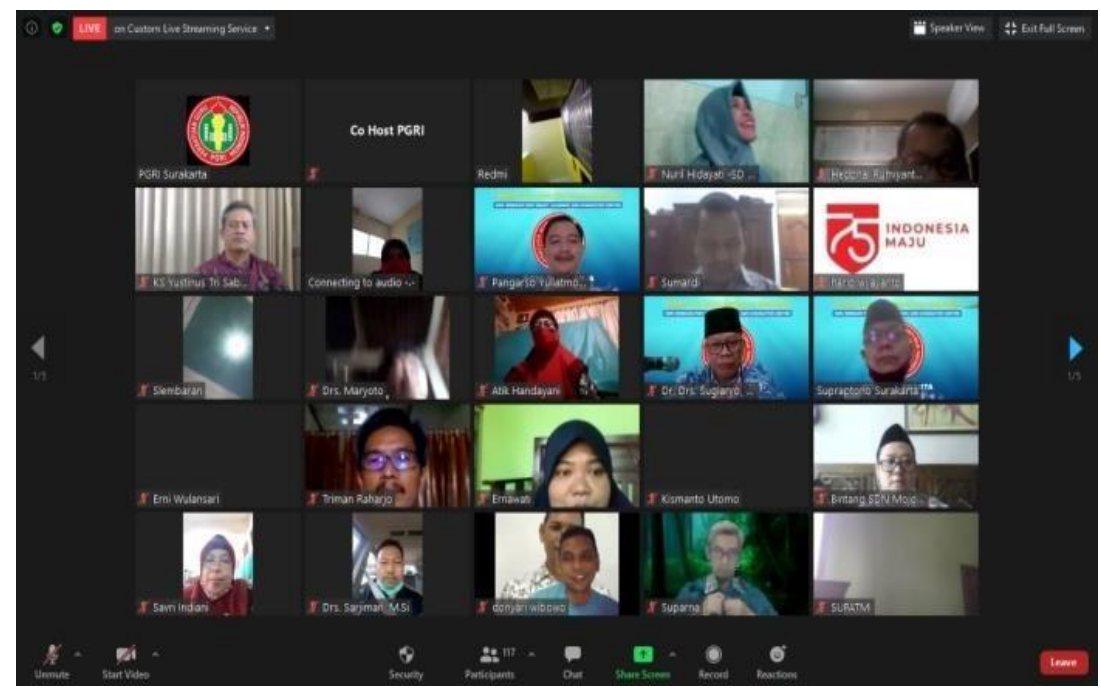

Gambar 3. kegiatan webinar dan diskusi (3)



Gambar 4. kegiatan webinar dan diskusi (4)

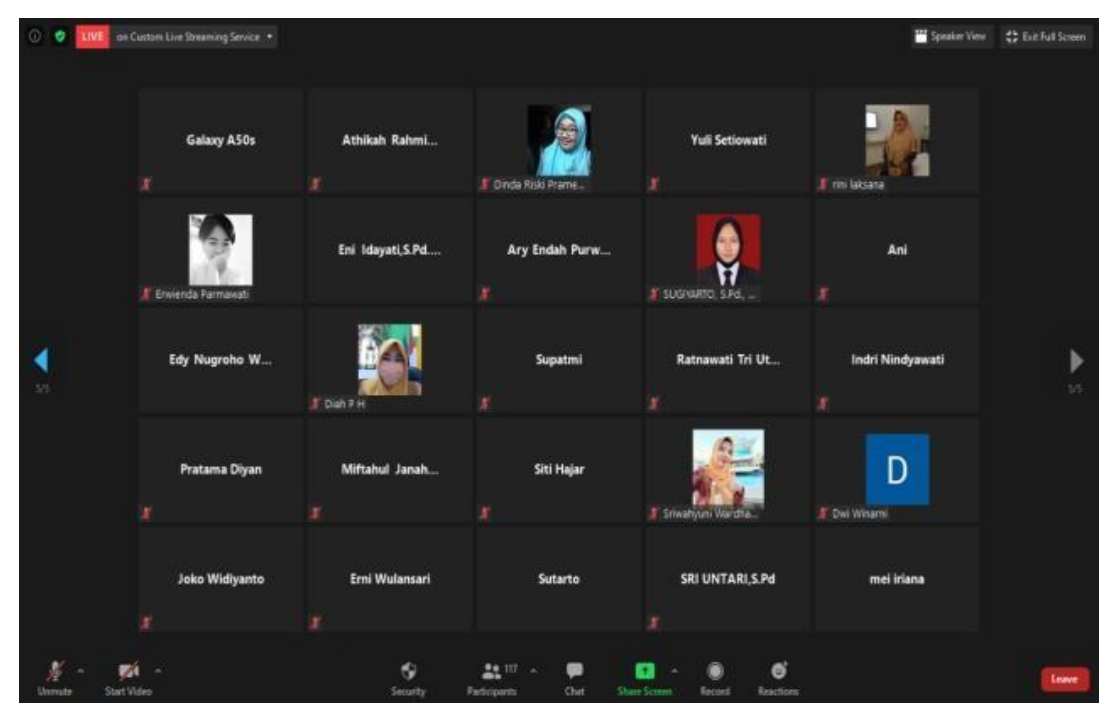

Gambar 5. kegiatan webinar dan diskusi (5) 
Sampai pada batas waktu pendampingan penyusunan proposal berakhir, kurang lebih menghasilkan 26 proposal PTK.

Berdasarkan proposal yang telah dikumpulkan terdapat beberapa kelemahan sebagai beikut: (1) Pada umumnya proposal itu bukan karya asli dari guru yang bersangkutan melainkan diambil dari penelitian tindakan kelas karya orang lain; (2) Permasalahan yang diajukan untuk dipecahkan sebagian besar sangatlah besar, serta berbelit belit sehingga lari dari masalah yang dihadapi di kelas dimana dia bertugas; (3) Dalam sub bagian kajian teori banyak ditemukan penulisan yang kurang pas atau relevan dengan permasalahan yang dikaji atau terlalu sederhana dan belum nampak wacana keilmuannya.

Mengingat masih dalam kondisi pandemi Covid-19 maka pendampingan PTK pelaksanaannya ditunda sampai setelah berakhirnya pandemi Covid-19 yang ditandai telah terjadinya pembelajaran secara tatap muka.umber tables consecutively in accordance with their appearance in the text. Place footnotes to tables below the table body and indicate them with superscript lowercase letters. Avoid vertical rules. Be sparing in the use of tables and ensure that the data presented in tables do not duplicate results described elsewhere in the article.

\section{KESIMPULAN DAN SARAN}

A. KESIMPULAN

Berdasarkan hasil pengamatan setelah dilaksanakan program pengabdian kepada masyarakat tentang peningkatan profesionalisme guru pada masa pandemi Covid-19 dapat disimpulkan bahwa:

1. Guru-guru SD/MI, SMP/MTS, dan SMA/SMK/MA tampak antusias dan bersemangat mengikuti kegiatan pengabdian ini. Hal ini ditunjukan dari banyaknya peserta didalam kegiatan webinar maupun bersemangat dalam mengikuti pendampingan penyusunan proposal PTK.

2. Belum maksimalnya secara kuantitatif dokumen usulan PTK yang dibuatoleh guru-guru SD/MI, SMP/MTS, dan SMA/SMK/MA kota Surakarta lebih disebabkan karena suasana masih dalam masa pandemi Covid-19. 


\section{B. SARAN}

1. Agar dapat diperoleh hasil yang maksimal kegiatan pengabdian kepada masyarakat ini sebaiknya diselenggarakan secara terprogram setiap semester.

2. Agar tim pengabdian kepada masyarakat Progdi PPKN FKIP UNISRI juga merencanakan kegiatan pelatihan penulisan hasil PTK yang dapat dimuat dalam jurnal ilmiah yang ber-ISSN.

3. Melaksanakan kegiatan berupa lokakarya ataupun pelatihan bagi guru dengan tema seputar penulisan karya ilmiah. 


\section{DAFTAR PUSTAKA}

Arikunto, Suharsimi. 2008. Penelitian Tindakan Kelas . Jakarta: Bumi Aksara

Ekawarna. (2010). Penelitian Tindakan Kelas. Penerbit Gaung Persada (GP Press): Jakarta

Hopkins. 1993. A Teacher's Guide to Classroom Research. Philadelphia. Open University Press.

Kemmis, S. \& Mc. Taggart, R. 1988. The Action Research Planner. Victoria: Deakin. University Press

Natawidjaja, Rochman.2009 .Penelitian Tindakan Kelas. Jakarta: Bumi Aksara.

Sugiyanto. 2009. Model-Model Pembelajaran Inovatif. Surakarta: Yuma Pustaka

Suwandi, Sarwiji.2009. Penelitian Tindakan Kelas. Surakarta: Yuma Pus 